\title{
Support for an independent familial segregation of executive and intelligence endophenotypes in ADHD families
}

\author{
N. N. J. Rommelse ${ }^{1 *}$, M. E. Altink ${ }^{2}$, J. Oosterlaan ${ }^{1}$, C. J. M. Buschgens ${ }^{2}$, J. Buitelaar ${ }^{2}$ \\ and J. A. Sergeant ${ }^{1}$ \\ ${ }^{1}$ Department of Clinical Neuropsychology, VU University Amsterdam, Amsterdam, The Netherlands \\ ${ }^{2}$ Department of Psychiatry, Radboud University Nijmegen Medical Center, Nijmegen, The Netherlands
}

Background. Impairments in executive functioning (EF) and intelligence quotient (IQ) are frequently observed in children with attention deficit hyperactivity disorder (ADHD). The aim of this paper was twofold: first, to examine whether both domains are viable endophenotypic candidates for ADHD and second to investigate whether deficits in both domains tend to co-segregate within families.

Method. A large family-based design was used, including 238 ADHD families (545 children) and 147 control families (271 children). Inhibition, visuospatial and verbal working memory, and performance and verbal IQ were analysed.

Results. Children with ADHD, and their affected and non-affected siblings were all impaired on the EF measures and verbal IQ (though unimpaired on performance IQ) and all measures correlated between siblings. Correlations and sibling cross-correlations were not significant between EF and IQ, though they were significant between the measures of one domain. Group differences on EF were not explained by group differences on IQ and vice versa. The discrepancy score between EF and IQ correlated between siblings, indicating that siblings resembled each other in their EF-IQ discrepancy instead of having generalized impairments across both domains. Siblings of probands who had an EF but not IQ impairment, showed a comparable disproportionate lower EF score in relation to IQ score. The opposite pattern was not significant.

Conclusions. The results supported the viability of EF and IQ as endophenotypic candidates for ADHD. Most findings support an independent familial segregation of both domains. Within EF, similar familial factors influenced inhibition and working memory. Within IQ, similar familial factors influenced verbal and performance IQ.

Received 11 June 2007; Revised 6 November 2007; Accepted 18 December 2007; First published online 8 February 2008

Key words: Attention deficit hyperactivity disorder, endophenotype, executive functions, intelligence, sibling.

\section{Introduction}

Executive functioning (EF) is probably the most extensively studied domain in attention deficit hyperactivity disorder (ADHD) (APA, 1994; Pennington \& Ozonoff, 1996; Clark et al. 2000; Sergeant et al. 2002; Seidman et al. 2004; Boonstra et al. 2005; Willcutt et al. 2005; Doyle, 2006). EF has been defined as 'those capacities that enable a person to engage successfully in independent, purposive, self-serving behaviour' (Lezak, 1995). EF impairments have been reported in many studies with ADHD patients, with problems in inhibition and working memory being the most frequently replicated (Pennington \& Ozonoff, 1996;

* Address for correspondence: N. N. J. Rommelse, M.S., VU University Amsterdam, Department of Clinical Neuropsychology, Van der Boechorststraat 1, 1081 BT Amsterdam, The Netherlands. (Email: nnj.rommelse@psy.vu.nl)
Clark et al. 2000; Sergeant et al. 2002; Seidman et al. 2004; Boonstra et al. 2005; Willcutt et al. 2005; Doyle, 2006). EF impairments appear to be (partly) related to abnormalities in the frontal lobe and frontalsubcortical structures found in patients with ADHD (Castellanos \& Tannock, 2002; Durston, 2003), since frontal lesions sometimes produce symptoms as observed in patients with ADHD (i.e. distractibility, hyperactivity, and impulsivity) as well as deficits on EF tasks (Mattes, 1980; Stuss \& Benson, 1986; Benson, 1991; Heilman et al. 1991; Fuster, 1997; Willcutt et al. 2005).

An issue related to $\mathrm{EF}$ in $\mathrm{ADHD}$ is intelligence. Intelligence may be defined as 'the aggregate or global capacity of the individual to act purposefully, to think rationally and to deal effectively with his environment' (Wechsler, 1944). Several parallels emerge between both domains. Like EF, a widespread finding 
across studies is a somewhat lower intelligence quotient (IQ) in children with ADHD (Mariani \& Barkley, 1997; Frazier et al. 2004; Kuntsi et al. 2004), having on average a 7- to 12-point lower full-scale IQ than controls with effect sizes being somewhat larger for verbal IQ (VIQ) than performance IQ (PIQ) (Frazier et al. 2004; Kuntsi et al. 2004). Furthermore, like EF, IQ seems to be (at least partly) mediated by frontal circuits (Duncan et al. 1995, 1996; Gray et al. 2003; Haier et al. 2004; Toga \& Thompson, 2005). Both EF and IQ are substantially influenced by heritability (Doyle et al. 2005b; Plomin \& Spinath, 2005). Previous research has shown certain polymorphisms in genes that relate to ADHD (DRD4 and DAT1) that are also related to both EF and IQ (Kuntsi et al. 2004; Doyle et al. 2005b; Khan \& Faraone, 2006; Mill et al. 2006; Boonstra et al. 2007).

Unclear from the majority of studies reporting on $\mathrm{EF}$ and IQ in patients with ADHD is whether problems in EF and IQ are causally related to ADHD, or are merely associated with the disorder. From an aetiological perspective, EF and IQ impairments may give rise to behavioural symptoms of inattention and hyperactivity-impulsivity. However, the reverse is also possible: being more inattentive and hyperactive-impulsive may cause abnormal performance on tasks measuring EF and IQ. In the latter case, EF and IQ impairments may not shed light on the neuro(psycho)logical causes leading up to ADHD but merely reflect an association with the disorder.

Research into non-affected siblings may help distinguish between these two alternatives: non-affected siblings do not suffer from ADHD, which makes it unlikely that the possible neuro(psycho)logical dysfunctions observed in this group are a result of inattention and hyperactivity-impulsivity. If EF and IQ impairments are indeed found in non-affected relatives, it is possible that EF and IQ dysfunctions form endophenotypes of ADHD: heritable, vulnerability traits that heighten the risk for developing the disorder (Gottesman \& Gould, 2003; Waldman, 2005). Non-affected siblings share on average half of their genes with their affected sibling and will, therefore, probably carry some of the susceptibility genes for ADHD. This underlying susceptibility for the disorder expresses itself in subtle neuro(psycho)logical abnormalities that may be picked up by sensitive neuro(psycho)logical tasks but are not sufficient to cause the behavioural symptoms of inattention and hyperactivity-impulsivity. Such endophenotypes may be useful in genetic research, since it is theorized that they relate more strongly to susceptibility genes for ADHD than behavioural symptoms (Gottesman \& Gould, 2003; Waldman, 2005). Therefore, the first aim of our study was to investigate whether EF and
IQ form candidate endophenotypes for ADHD. We limited our investigation of EF to inhibition and working memory, since deficits in these two functions are the most reliably replicated ones in ADHD and both functions have been put forward as the most likely endophenotypic candidates within the EF domain (Castellanos \& Tannock, 2002). If EF and IQ impairments are indeed viable endophenotypic candidates, it may be expected that non-affected siblings portray problems in both domains and that siblings resemble each other in EF and IQ.

Few studies have targeted EF and IQ within ADHD families and results appear inconsistent. Two studies have failed to find neurocognitive impairments in parents of children with ADHD (Murphy \& Barkley, 1996; Asarnow et al. 2002). Another study found no impairment on isolated measures of EF in non-affected siblings of males with ADHD, although a composite of EF measures nearly $(p=0.06)$ differentiated nonaffected siblings from controls (Seidman et al. 2000). Another study reported that a variety of EF measures was familial but only a minority of the measures demonstrated impairments in the non-affected relatives (Nigg et al. 2004). More promising results have been reported by Waldman et al. (2006), showing that various EF measures are impaired in non-affected siblings and correlated between siblings; also, a study focusing on twins discordant for ADHD reported on various EF measures as endophenotypic candidates (Bidwell et al. 2007). Studies that have specifically targeted inhibition as a cognitive endophenotype have also reported promising results: two studies reported non-affected siblings as performing intermediately between their affected siblings and controls (SlaatsWillemse et al. 2003; Schachar et al. 2005) and a third study reported that poor inhibition in children with ADHD was related to a higher prevalence of ADHD among their relatives (Crosbie \& Schachar, 2001). Subtle problems in interference control have been reported in non-affected relatives of girls with ADHD (Doyle et al. 2005a) and significant correlations have been found for inhibitory control between affected siblings (Slaats-Willemse et al. 2005). These findings suggest that inhibition may be a viable executive function to serve as an endophenotype, since it appears deficient (to a certain degree) in non-affected relatives of ADHD patients and correlates between siblings. No such data have been reported on working memory in non-affected siblings. With respect to IQ, two studies have reported lower IQ in relatives of ADHD patients (Faraone et al. 1993, 1996). These studies suggest that there may be some impairment in EF and IQ in non-affected relatives, though these impairments are not found on all EF tasks and the effect appears to be small. Clearly, research is needed 
to further explore the utility of EF and IQ as endophenotypes for ADHD.

An unaddressed issue in all these studies with ADHD patients and their relatives is the interrelatedness between EF and IQ. Although EF and IQ appear to bear some parallels at the behavioural, neurological, and genetic levels, the relationship between EF and IQ is a complex one. In various studies using ADHD patients and control subjects, a positive relationship has been found between EF and IQ (Bull \& Scerif, 2001; Miyake et al. 2001; Mahone et al. 2002; Gray et al. 2003). Different explanations have been offered: EF underlies a lower IQ, or vice versa that IQ is at the heart of EF, or that there is no hierarchical relationship between both domains but both domains share common causes (Schretlen et al. 2000; Engle, 2002; Conway et al. 2003). In latter case, it is expected that problems in EF and IQ co-segregate within families. If so, data will indicate that (1) EF of a child will relate to IQ in their siblings and vice versa; (2) a principal component analysis on all measures will not reveal a clear independence of EF and IQ; (3) impairment in one domain is related to impairment in the other domain; (4) children selectively impaired in one but not the other domain will have siblings displaying generalized (but not specific) impairments across domains. Thus, this study will address two issues: (a) whether or not EF and IQ form viable endophenotypes of ADHD and $(b)$ whether or not EF and IQ have shared underpinnings, in which case both functions will cosegregate.

\section{Method}

\section{Participants}

Families with at least one child with the combined subtype of ADHD (proband) and at least one additional sibling (regardless of possible ADHD status) were recruited in order to participate in the Dutch part of the International Multicenter ADHD Genes study (IMAGE). The IMAGE project is an international collaborative study that aims to identify genes that increase the risk for ADHD using QTL linkage and association strategies (Brookes et al. 2006). Probands were required to have the combined subtype of ADHD, because this most severe subtype of ADHD would probably provide the best results for linkage and association. Additional control families were recruited from primary and high schools from the same geographical regions as the participating ADHD families. Controls and their first-degree relatives were required to have no formal or suspected ADHD diagnosis. All children were between the ages of 5 and 19 years and were of European Caucasian descent.
Participants were excluded if they had an IQ $<70$, a diagnosis of autism, epilepsy, general learning difficulties, brain disorders or known genetic disorders, such as Down's syndrome or Fragile-X-syndrome. A total of 238 ADHD families and 147 control families fulfilled inclusion and exclusion criteria. Within the ADHD families, 238 probands (all with combined subtype ADHD), 112 affected siblings (64 with combined subtype, 28 with inattentive subtype and 20 with hyperactive-impulsive subtype) and 195 non-affected siblings participated. Control families consisted of 271 children. For 51 control children, no additional control sibling could be recruited for the study, because the sibling was either unwilling to participate or because the control family consisted of only one child.

Both the children already clinically diagnosed with ADHD and their siblings were similarly screened using the standard procedures of the IMAGE project described fully elsewhere (Brookes et al. 2006; Rommelse et al. 2007). Briefly, parent and teacher screening questionnaires-Conners' long version (Conners, 1996) and Strengths and Difficulties Questionnaire (Goodman, 1997) - and a semi-structured, ostandardized, investigator-based interview 'Parental Account of Children's Symptoms' (PACS) (Taylor, 1986) were used to identify children with ADHD symptoms [see Rommelse et al. (2007) for the standardized algorithm that was applied to the data to derive each of the 18 DSM-IV ADHD symptoms, providing operational definitions for each behavioural symptom]. The Conners' long version for both parents and teachers was completed for control children. Table 1 provides the characteristics of the four groups.

\section{Procedure}

The tasks described in this study were part of a broader neuropsychological assessment battery used in the Dutch part of the IMAGE study (Rommelse et al. 2007). Administration of the entire battery (including breaks) required about $3-4 \mathrm{~h}$. Testing of children with ADHD and their siblings took place at the VU Amsterdam or at the Radboud University Nijmegen Medical Centre and was conducted simultaneously for all children within a family. Medication to reduce the symptoms of ADHD was discontinued for at least $48 \mathrm{~h}$ (stimulants) or longer (non-stimulants) to allow sufficient washout before testing took place (Pelham et al. 1999). Control children were tested in a similar way in a quiet room at their school. Children were motivated with small breaks. At the end of the session, a gift worth approximately 4 was given. Written informed consent was obtained from children aged $\geqslant 12$ years and the parents prior to the study. The study had medical-ethical approval. 
Table 1. Sample characteristics

\begin{tabular}{|c|c|c|c|c|c|c|}
\hline & $\begin{array}{l}\text { Probands } \\
(n=238)\end{array}$ & $\begin{array}{l}\text { Affected } \\
\text { siblings } \\
(n=112)\end{array}$ & $\begin{array}{l}\text { Non-affected } \\
\text { siblings } \\
(n=195)\end{array}$ & $\begin{array}{l}\text { Normal } \\
\text { controls } \\
(n=271)\end{array}$ & $F_{3,812}$ & $\begin{array}{l}\text { Contrasts }{ }^{\mathrm{a}} \text { based } \\
\text { on } p \text { values of } 0.05\end{array}$ \\
\hline Age (years) & $12.0(2.5)$ & $12.0(3.4)$ & $11.5(3.6)$ & $11.6(3.2)$ & N.S. & \\
\hline Right handed (\%) & 91.1 & 87.5 & 89.2 & 85.5 & N.s. ${ }^{b}$ & \\
\hline Male (\%) & 84.5 & 56.3 & 45.1 & 40.6 & $113.9^{* \mathrm{~b}}$ & $\begin{array}{l}1>2,3,4 \\
2=3 \text { and } 2>4 \\
3=4\end{array}$ \\
\hline Estimated full-scale IQ & $97.9(13.0)$ & $100.7(10.6)$ & $103.8(10.9)$ & $106.0(10.2)$ & $23.5^{*}$ & $\begin{array}{l}1=2 \text { and } 1<3=4 \\
2=3 \text { and } 2<4 \\
3=4\end{array}$ \\
\hline \multicolumn{7}{|l|}{ Conners' parent DSM-IV } \\
\hline Inattentive & $71.1(8.4)$ & $66.0(11.6)$ & $47.9(7.0)$ & $46.5(4.8)$ & $585.4^{*}$ & $1>2>3=4$ \\
\hline Hyperactive-impulsive & $79.1(9.2)$ & $67.8(13.6)$ & $49.0(6.9$ & $47.3(5.1)$ & $767.3^{*}$ & $1>2>3=4$ \\
\hline Total & $76.9(8.6)$ & $68.3(11.6)$ & $48.2(6.8)$ & $46.5(4.5)$ & $875.7^{*}$ & $1>2>3=4$ \\
\hline \multicolumn{7}{|l|}{ Conners' teacher DSM-IV } \\
\hline Inattentive & $66.0(9.1)$ & $61.7(10.2)$ & $48.3(6.0)$ & $46.4(4.6)$ & $386.3^{*}$ & $1>2>3=4$ \\
\hline Hyperactive-impulsive & $70.2(10.7)$ & $63.5(13.3)$ & $48.3(6.5)$ & $47.2(5.0)$ & $378.1^{*}$ & $1>2>3=4$ \\
\hline Total & $69.8(9.8)$ & $63.8(11.4)$ & $48.3(5.8)$ & $46.4(4.5)$ & $485.8^{*}$ & $1>2>3=4$ \\
\hline \multicolumn{7}{|l|}{ ADHD diagnosis } \\
\hline Inattentive $(n)$ & - & 28 & - & - & & \\
\hline Hyperactive-impulsive $(n)$ & - & 20 & - & - & & \\
\hline Combined $(n)$ & 238 & 64 & - & - & & \\
\hline
\end{tabular}

N.s., Not significant; DSM-IV, Diagnostic and Statistical Manual for Mental Disorders (4th edn); ADHD, attention deficit hyperactivity disorder; S.D., standard deviation.

Values are given as mean (S.D.) unless otherwise specified.

${ }^{\text {a }}$ Contrasts : 1 = probands, $2=$ affected siblings, $3=$ non-affected siblings, $4=$ normal controls. ${ }^{\mathrm{b}} \chi^{2}$ test.

${ }^{*} p<0.001$.

\section{Measures}

\section{Inhibition}

The Stop task was used to measure speed and accuracy of inhibition of an ongoing response (Logan \& Cowan, 1984; Logan, 1994). Subjects were presented two types of trials: go-trials and stop-trials. Go-trials consisted of the presentation of a go-stimulus (drawing of a plane) that was either pointing to the right or to the left (Scheres et al. 2006). Children were instructed to press a response button that corresponded to the direction of the stimulus as quickly and as accurately as possible. Stop-trials were identical to the go-stimulus but in addition a stop-signal was presented (drawing of a cross that was superimposed on the plane). Children were required to withhold their response to the stop-signal. Go-stimuli were displayed for $1000 \mathrm{~ms}$, preceded by a $500 \mathrm{~ms}$ fixation point. Stopsignals were displayed for $1000 \mathrm{~ms}$ minus delay time. Inter-trial intervals were $3000 \mathrm{~ms}$. The delay between the go- and stop-signal was dynamically varied so that the child successfully inhibited $50 \%$ of the stop-trials and unsuccessfully inhibited the other $50 \%$. At this point, the go-process and stop-process are of equal duration, which makes it possible to estimate the latency of the stop-process: the stop signal reaction time (SSRT) (Logan, 1994). A total of two practice blocks and four experimental blocks were administered, each consisting of 60 trials. The first practice block consisted of only go-trials. The second practice block and the four experimental blocks consisted of $75 \%$ go-trials and $25 \%$ stop-trials. Go- and stop-trials were pseudorandomly presented. Task administration took about $15 \mathrm{~min}$. The SSRT and the percentage of commission errors (\% commission errors) were used as dependent measures reflecting inhibitory processing.

\section{Visuospatial working memory}

The visuospatial sequencing task was used to measure accuracy of visuospatial working memory (De Sonneville, 1999). Stimuli consisted of nine circles symmetrically organized in a square $(3 \times 3)$. On each trial, a sequence of circles was pointed at by a computer-driven hand. Subjects were instructed to replicate the exact same sequence of circles, by pointing to 
them with the small, self-driven hand. There were no time constrictions. One practice trial and 24 experimental trials were presented. Every succeeding trial increased in difficulty level: an increase in the number of circles required to be remembered and/or an increase in the complexity of the spatial pattern (i.e. the trial consisted of circles that were spatially further removed from one another instead of being close to one another), hence manipulating working memory demands. Task administration took about $7 \mathrm{~min}$. Two dependent measures were used: the total number of identified targets (NIT) and total number of identified targets in the correct order (NITco). The NITco is a stricter working memory measure, because it takes into account both the target identification as well as the order of the targets.

\section{Verbal working memory}

The maximum span of the digit span forwards and backwards of the WISC-III and WAIS-III (Wechsler, $2000,2002)$ was used to obtain an indication of verbal working memory.

\section{Intelligence}

Full-scale IQ was estimated by four subtests of the Wechsler Intelligence Scale for Children, 3rd edition (WISC-III) or the Wechsler Adult Intelligence Scale, 3rd edition (WAIS-III) (Wechsler, 2000, 2002) (depending on the child's age): vocabulary, similarities, block design and picture completion. These subtests are known to correlate between 0.90 and 0.95 with the fullscale IQ (Groth-Marnat, 1997). As dependent measures in further analyses we used PIQ (summed scaled scores of block design and picture completion) and VIQ (summed scaled scores of vocabulary and similarities).

\section{Statistical analyses}

Due to technical problems, the Stop task was not administered to 63 children within the ADHD families (28 probands, 12 affected siblings, 23 non-affected siblings) and 12 control children. Furthermore, a slightly different version of the Stop task was administered to 31 children within the ADHD families (13 probands, five affected siblings, 13 non-affected siblings), in which control trials were implemented (stop-signal appeared before the go-signal). Data analyses were performed with and without including the data of these families, which revealed the same results. Therefore, results are reported including all of these families. The percentage of missing data for all other measures was random and less than $5 \%$ and missing values were replaced by multiple imputations using the expectation maximization algorithm (Tabachnick \& Fidell, 2001). Measures were successfully normalized by applying a Van der Waerden transformation (SPSS version 14; SPSS Inc., Chicago, IL, USA). The $z$ scores of the inhibition measures (SSRT and \% commission errors) were mirrored, so that the $z$ scores of all dependent measures would have the same meaning: a higher $z$ score indicated better performance. Results were similar, when based on raw, unstandardized task measures and when based on normalized, standardized task measures. We set $\alpha$ at 0.05 . Following Cohen's guidelines (Cohen, 1988), effect sizes were defined in terms of the percentage of variance explained : $1 \%, 9 \%$ and $25 \%$ were used to define small, medium and large effects (these figures translate into $\eta^{2}$ values of $0.01,0.06$ and $0.14)$.

The viability of the measures as endophenotypes of ADHD (first study aim) was tested by calculating group differences using a linear mixed model with group (four groups: proband, affected sibling, nonaffected sibling, and control) and gender as factors, age as a covariate, and family as a random effect to account for within-family correlation. Group contrasts were calculated within the mixed model using pairwise comparisons with age as covariate. Sibling correlations (pairwise correlations) were calculated to investigate resemblance between siblings for the various measures [S.A.G.E. (Statistical Analysis for Genetic Epidemiology) 5.3.1, 2007; Case Western Reserve University, Cleveland, OH, USA; http:// darwin.cwru.edu/sage/].

The co-segregation of EF and IQ (second study aim) was tested by calculating sibling cross-correlations in order to examine whether EF of a child would relate to IQ in his/her siblings and vice versa. This would suggest similar familial factors underlay both domains. Thereafter, a principal component analysis was run on the measures to examine whether or not it was possible to discriminate between two separate components (EF and IQ). These components were then used to test whether group differences in one domain would diminish/disappear, when corrected for group differences in the other domain. Last, a discrepancy score was calculated by subtracting the IQ component $z$ score from the EF component $z$ score. Sibling correlations for this discrepancy score were calculated to examine whether EF-IQ discrepancy was familial. Also, a subsample of probands was selected that was predominantly impaired in one but not the other domain (more than 1.5 S.D. difference between performances in both domains). It was analysed whether or not a similar domain discrepancy would be observed in their siblings. 
(a)

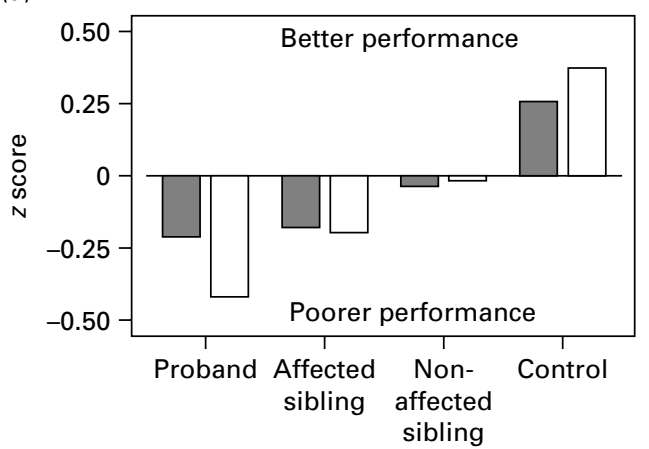

(c)

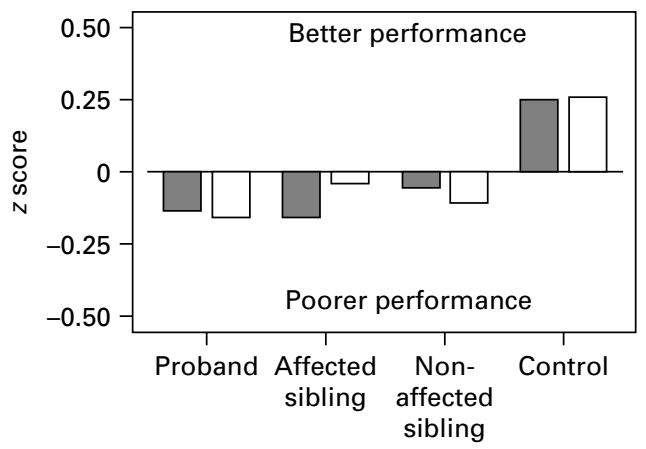

(b)

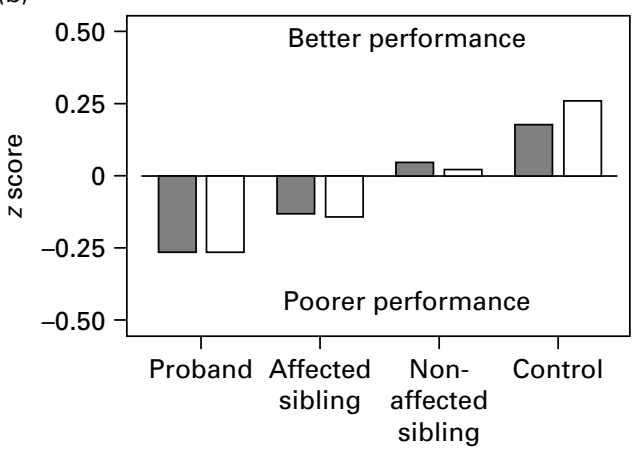

$(d)$

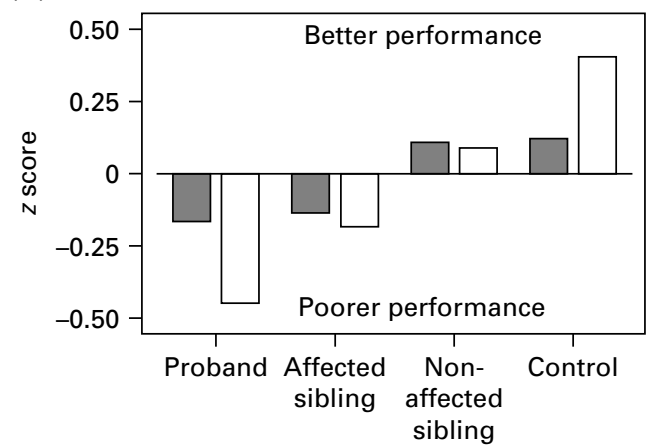

Fig. 1. Differences between probands, affected siblings, non-affected siblings and controls on measures of $(a)$ inhibition ( $\square$, stop signal response time; $\square$, percentage commission errors); (b) visuospatial working memory $(\square$, number of correct targets;

$\square$, number of correct targets in correct order); (c) verbal working memory ( $\square$, digit span forwards; $\square$, digit span backwards);

(d) intelligence $(\square$, performance intelligence quotient; $\square$, verbal intelligence quotient).

\section{Results}

\section{EF and IQ as candidate endophenotypes}

To test whether children with ADHD (probands and affected siblings) and, possibly, their non-affected siblings were impaired in inhibition, working memory and intelligence measures, linear mixed models were used (separately for each task measure) as described above. Results are presented in Fig. 1 and Table 2.

Group differences were found on all EF and IQ measures, with small to medium effect sizes. Probands and affected siblings performed overall very similarly on EF and IQ measures (except for NIT of visuospatial working memory and VIQ, on which probands performed worse than affected siblings) and both groups differed significantly from controls on all measures, indicating ADHD to be associated with generalized impairments in both EF and IQ. Non-affected siblings were impaired compared with controls on almost all measures, except on NIT of visuospatial working memory and PIQ. The first finding may indicate that the basic visuospatial memory span of non-affected siblings is normal, but if greater working memory demands are required (like on the NITco variable), deficits in visuospatial working memory will surface.
The latter may indicate that PIQ is less suitable as an endophenotypic candidate than VIQ. On most measures, non-affected siblings performed in between their affected siblings and controls. Sibling correlations were calculated to examine whether siblings resembled each other in EF and IQ. As is shown in Table 3, all measures significantly correlated between siblings (between 0.15 and 0.30 ), suggesting EF and IQ to be familial.

\section{Co-segregation of EF and IQ}

Almost none of the sibling cross-correlations between the EF and IQ measures were significant, suggesting differential familial influences related to EF and IQ. However, the majority of sibling cross-correlations between the EF measures were significant (i.e. inhibitory measures in a child correlated with working memory measures in his/her siblings), suggesting similar familial influences affected both deficits in inhibition and working memory (Table 3). The same was true for VIQ and PIQ.

A principal component analysis revealed a twocomponent solution (see Fig. 2), with the first component explaining $42 \%$ of the variance on which all EF 
Table 2. Inhibition, working memory and intelligence

\begin{tabular}{|c|c|c|c|c|c|c|c|}
\hline Dependent variable & $\begin{array}{l}\text { Mean } \\
\text { (S.E.) }\end{array}$ & $\begin{array}{l}\text { Mean } \\
\text { (S.E.) }\end{array}$ & $\begin{array}{l}\text { Mean } \\
\text { (S.E.) }\end{array}$ & $\begin{array}{l}\text { Mean } \\
\text { (S.E.) }\end{array}$ & $F^{\mathrm{a}}$ & $\eta_{\mathrm{p}}^{2}$ & $\begin{array}{l}\text { Contrasts }^{\mathrm{a}} \\
(p \leqslant 0.05)\end{array}$ \\
\hline \multicolumn{8}{|l|}{ Inhibition } \\
\hline Stop signal reaction time & $285.9(4.3)$ & $284.2(5.7)$ & $274.1(4.5)$ & $251.0(4.0)$ & $F(3,477.6)=13.02$ & 0.05 & $\begin{array}{l}1=2,2=3 \\
1>3,1,2,3>4\end{array}$ \\
\hline Commission errors $(\%)$ & $3.1(0.2)$ & $2.9(0.2)$ & $2.3(0.2)$ & $1.4(0.1)$ & $F(3,488.1)=21.03$ & 0.08 & $1=2>3>4$ \\
\hline \multicolumn{8}{|l|}{ Visuospatial working memory } \\
\hline Number of correct targets & $100.9(0.2)$ & $101.5(0.3)$ & $102.2(0.2)$ & $102.5(0.2)$ & $F(3,546.2)=15.62$ & 0.07 & $1<2<3=4$ \\
\hline $\begin{array}{l}\text { Number of correct targets } \\
\text { in correct order }\end{array}$ & $87.2(0.6)$ & $88.9(0.8)$ & $91.7(0.6)$ & $94.4(0.6)$ & $F(3,549.4)=27.74$ & 0.11 & $1=2<3<4$ \\
\hline \multicolumn{8}{|l|}{ Verbal working memory } \\
\hline Digit span forwards & $5.2(0.1)$ & $5.2(0.1)$ & $5.4(0.1)$ & $5.7(0.1)$ & $F(3,553.2)=11.70$ & 0.04 & $1=2=3<4$ \\
\hline Digit span backwards & $3.8(0.1)$ & $3.9(0.1)$ & $4.0(0.1)$ & $4.4(0.1)$ & $F(3,548.2)=13.15$ & 0.05 & $1=2=3<4$ \\
\hline \multicolumn{8}{|l|}{ Intelligence } \\
\hline Performance IQ & $20.4(0.3)$ & $20.6(0.4)$ & $21.8(0.3)$ & $21.8(0.3)$ & $F(3,522.0)=5.53$ & 0.02 & $1=2<3=4$ \\
\hline Verbal IQ & $18.5(0.3)$ & $19.8(0.4)$ & $20.9(0.3)$ & $22.7(0.3)$ & $F(3,526.9)=29.82$ & 0.12 & $1<2<3<4$ \\
\hline
\end{tabular}

S.E., Standard error; IQ, intelligence quotient.

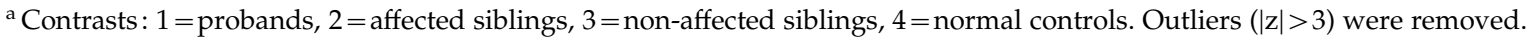
The $F$ statistic and contrasts are based on a linear mixed model with group and gender as factors, age as covariate and family as random effect. Results are similar when based on raw, unstandardized task measures and when based on normalized, standardized task measures.

Table 3. Cross-correlations between siblings for measures of executive and intellectual functioninga

\begin{tabular}{|c|c|c|c|c|c|c|c|c|}
\hline & \multicolumn{8}{|c|}{ Sibling 2} \\
\hline & 1 & 2 & 3 & 4 & 5 & 6 & 7 & 8 \\
\hline \multicolumn{9}{|l|}{ Sibling 1} \\
\hline \multicolumn{9}{|l|}{ Inhibition } \\
\hline 1. Stop signal reaction time & $0.22^{*}$ & $0.16^{*}$ & $0.15^{*}$ & $0.13^{*}$ & 0.05 & $0.12^{*}$ & 0.03 & 0.01 \\
\hline 2. $\%$ Commission errors & & $0.19^{*}$ & $0.10^{*}$ & $0.10^{*}$ & 0.04 & $0.08^{*}$ & $0.08^{*}$ & 0.07 \\
\hline \multicolumn{9}{|l|}{ Visuospatial working memory } \\
\hline 3. Number of correct targets & & & $0.19^{*}$ & $0.19^{*}$ & 0.06 & $0.16^{*}$ & 0.06 & 0.01 \\
\hline $\begin{array}{l}\text { 4. Number of correct targets } \\
\text { in correct order }\end{array}$ & & & & $0.20^{*}$ & $0.08^{*}$ & $0.19^{*}$ & 0.07 & 0.05 \\
\hline \multicolumn{9}{|l|}{ Verbal working memory } \\
\hline 5. Digit span forwards & & & & & $0.15^{*}$ & $0.13^{*}$ & 0.03 & 0.04 \\
\hline 6. Digit span backwards & & & & & & $0.17^{*}$ & 0.02 & 0.02 \\
\hline \multicolumn{9}{|l|}{ Intelligence } \\
\hline 7. Performance IQ & & & & & & & $0.30^{*}$ & $0.19^{*}$ \\
\hline 8. Verbal IQ & & & & & & & & $0.31^{*}$ \\
\hline
\end{tabular}

IQ, Intelligence quotient.

${ }^{a}$ Correlations are based on all participants.

* Significant $(p \leqslant 0.05)$.

measures highly loaded ( $r$ between 0.65 and 0.85), but to a significantly lesser degree the IQ measures (both $r=0.23$ ). The second component explained 17\% of the variance on which both IQ measures highly loaded (both $r=0.81$ ) but not or to a significantly lesser degree the EF measures ( $r$ between 0.01 and 0.29 ). The first component was labelled 'EF component', the second component 'IQ component'. The components 


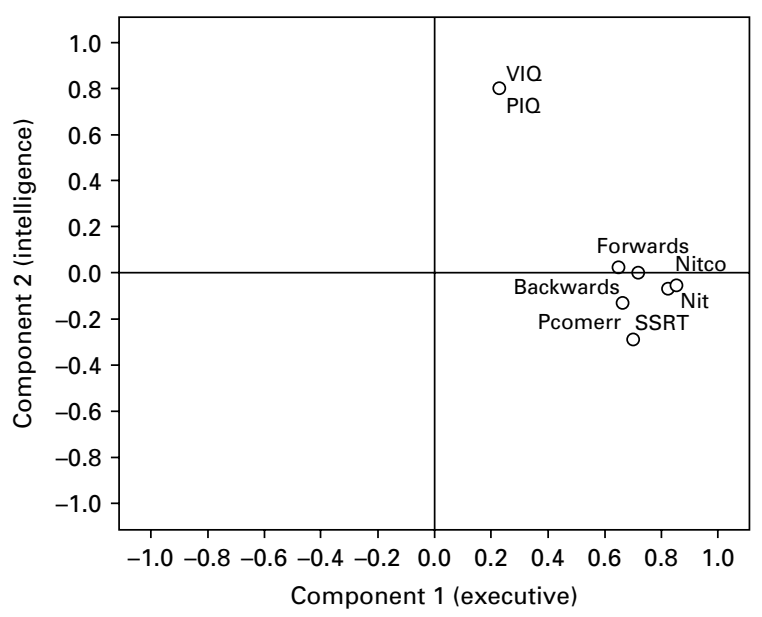

Fig. 2. Correlation plot. Component plot revealing that executive and intelligence measures form two relatively independent factors. Measures of intelligence are verbal intelligence quotient (VIQ) and performance IQ (PIQ). Measures of visuospatial working memory are number of identified targets (Nit) and number of identified targets in correct order (Nitco). Measures of verbal working memory are digit span forwards (Forwards) and digit span backwards (Backwards). Measures of inhibition are memory stop signal response time (SSRT) and percentage commission errors (Pcomerr).

correlated modestly with each other $(r=0.16)$. These findings indicate that EF and IQ are relatively independent of each other.

Group differences for the EF component remained significant, when the IQ component was implemented as covariate $[F(3,532.2)=37.70, p<0.001]$ : probands and affected siblings had a similar EF component $(p=0.31)$, and both groups had a poorer EF component than non-affected siblings $(p<0.001$ and $p=0.003$, respectively) and controls (both $p<0.001)$. Non-affected siblings also had a poorer EF component than controls $(p<0.001)$. Group differences also remained for the IQ component, when the EF component was implemented as covariate $[F(3,499.0)=8.71, p<0.001]$. Probands had a poorer IQ component than affected siblings $(p=0.03)$ and both groups had a poorer IQ component than controls $(p<0.001$ and $p=0.05)$. Nonaffected siblings had a better IQ component than probands $(p<0.001)$, but their IQ component did not differ significantly from affected siblings or controls ( $p=0.16$ and $p=0.44$, respectively). These findings suggest that EF impairments found in children with ADHD, and in their affected and non-affected siblings are not attributable to IQ impairments or in the reverse direction.

To further examine whether EF and IQ co-segregate within families, we tested whether the discrepancy score between EF and IQ ( $z$ score of the EF component minus the $z$ score of the IQ component) was unrelated between siblings. This was not the case $(r=0.24$, $p<0.001)$, suggesting a specific pattern of EF and IQ segregation within families. Partly similar results were found when we analysed this discrepancy score for siblings of two selected subsamples of probands displaying a large discrepancy (>1.5 s.D.) between their EF and IQ. A total of 24 probands had an EF component score that was disproportionally worse compared with their IQ component score (i.e. EF < IQ) and 28 probands who displayed the opposite pattern $(E F>I Q)$. We then tested whether their siblings displayed a less extreme discrepancy between EF and IQ by comparing the EF-IQ discrepancy score between the siblings and controls using the same linear mixed model described above. In contrast to expectations, the three groups differed significantly in the EF-IQ discrepancy score $[F(2,235.1)=8.15, p<0.001]$. Siblings of $\mathrm{EF}<\mathrm{IQ}$ probands showed a comparable $\mathrm{EF}<\mathrm{IQ}$ score, when compared with controls $(p<0.001)$. This $\mathrm{EF}<\mathrm{IQ}$ score differed significantly from zero $(t=4.19$, $p<0.001)$, suggesting that the disproportionate low EF score of the proband related specifically to a disproportionate low EF score (but not low IQ score) in the siblings. However, the opposite pattern $(\mathrm{EF}>\mathrm{IQ})$ was not significant, since the EF $>$ IQ score of siblings of $\mathrm{EF}>\mathrm{IQ}$ probands did not differ from controls $(p=0.58)$ and did not differ significantly from zero $(t=0.98$, $p=0.17)$. This may suggest that IQ impairments lead secondarily to EF impairments.

\section{Discussion}

We investigated whether measures of EF (inhibition, and visuospatial and verbal working memory) and IQ (PIQ and VIQ) would form candidate endophenotypes and if deficits in both domains co-segregate within families.

Our results indicate that all EF measures studied here appeared useful as endophenotypic candidates, since both probands, and affected and non-affected siblings showed deficits in the three EF domains studied and siblings resembled each other in EF. The findings of impaired EF in children with ADHD are in line with most previous studies on inhibition, visuospatial and verbal working memory in patients with ADHD (Oosterlaan \& Sergeant, 1996; Oosterlaan et al. 1998; Nigg, 1999; Martinussen et al. 2005). Much less is known about EF in relatives of children with ADHD, but our results are in line with previous studies on EF and other cognitive difficulties in non-affected siblings (Crosbie \& Schacher, 2001; Slaats-Willemse et al. 2003; Doyle et al. 2005a; Schachar et al. 2005; Waldman et al. 2006; Rommelse et al. 2007; Bidwell et al. 2007). The results suggest that deficits in EF form 
key neuropsychological endophenotypic candidates, as has been previously suggested (Castellanos \& Tannock, 2002). Similar group differences and sibling correlations were obtained for VIQ, suggesting that VIQ is an equally potent endophenotype. However, children with ADHD had only a slightly lower PIQ than controls in this study and non-affected siblings did not differ from controls in their PIQ. This suggests that VIQ may be more useful for genetic research than PIQ or a combination of these measures. Previous research has shown full-scale IQ to be genetically related to ADHD (Kuntsi et al. 2004; Doyle et al. 2005a; Mill et al. 2006), but it remains to be determined whether this is true for both PIQ and VIQ.

All in all, with respect to the first aim of our study, both EF and IQ showed endophenotypic-like group patterns (with small to medium effect sizes) and familial resemblance. With respect to the second aim of our study, almost all our findings indicate that EF and IQ impairments do not co-segregate within families. For example, EF in children did not relate to IQ in their siblings and vice versa, suggesting that different familial factors (genetic and environmental) gave rise to problems in both domains. Moreover, a principal component analysis revealed that EF and IQ are relatively independent of each other in the same child. This contrasts with some previous studies (Bull \& Scerif, 2001; Miyake et al. 2001; Mahone et al. 2002; Gray et al. 2003), but is in line with others (Welsh et al. 1991; Ardila et al. 2000; Polderman et al. 2006). The independence of both domains was further underlined, when group differences in one domain did not disappear when performance in the other domain was used as a covariate, as in other studies (Seidman et al. 1995 ; Barnett et al. 2001; Nigg et al. 2002; Oosterlaan et al. 2005) and suggests that EF impairments found in children with ADHD, and their affected and non-affected siblings are not attributable to IQ impairments or vice versa. Furthermore, the discrepancy between EF and IQ correlated between siblings, indicating siblings resembled each other in their EF-IQ discrepancy instead of having generalized impairments across both domains. This was also found when siblings of probands with EF (but not IQ) problems displayed the same selective EF (but not IQ) deficit, although the opposite pattern was not significant. The latter finding may suggest that even though EF-IQ discrepancy functioning correlates between siblings, extreme IQ impairment does not exist in the presence of normal EF in most siblings of such a proband. This may be explained as IQ impairments leading secondarily to EF impairments. Thus, a specific EF impairment in the absence of a lower IQ in a family appears supported by these findings, but when severe IQ impairments occur in a family, it is likely that some family members will also portray EF impairments. Overall, though, almost all findings support an independent segregation of EF and IQ.

The various measures within the EF domain were related to one another with correlations of medium size, suggesting the various constructs to be related, but not interchangeably, and this confirms previous findings (Miyake et al. 2000). Furthermore, most sibling cross-correlations for the EF measures reached significance, suggesting that problems in inhibition and working memory partly originate from the same familial sources. Similar results were found for both measures of IQ, suggesting VIQ and PIQ have similar familial underpinnings.

\section{Limitations}

Important aspects of $\mathrm{EF}$, such as cognitive flexibility and planning, have not been assessed here. It may be possible, therefore, that our findings do not generalize across the entire EF spectrum, but relate only to working memory and inhibition. Besides that, working memory may also be classified as a memory function (Smith \& Jonides, 1999) instead of an executive function. Furthermore, IQ, as measured here, is reduced to what is measured by Wechsler IQ subtests. Since only a few subtests were administered, it is not possible to discuss our findings in terms of crystalline and fluid intelligence (Duncan et al. 1996; Duncan, 2005), which would have made an interesting contribution to the study. It is possible that EF is related to fluid intelligence, but not necessarily as measured by the Wechsler IQ tests (Duncan et al. 1995).

\section{Conclusions}

The results supported the viability of EF and IQ as endophenotypic candidates, since children with ADHD, and their affected and non-affected siblings were all impaired on the EF measures and VIQ (though unimpaired in PIQ) and all measures correlated between siblings. However, difficulties in EF and IQ appear to exist relatively independently of each other and appear to originate from different familial sources. Within the EF domain, similar familial influences seemed to affect inhibition and working memory, suggesting that both functions have somewhat similar genetic and environmental underpinnings. Similar results were found for both measures of IQ, suggesting VIQ and PIQ have similar familial underpinnings.

\section{Acknowledgements}

This study was partly funded by a grant assigned to Professor Dr Faraone by the National Institute of Mental Health (NIH grant no. R01 MH62873-01A1). 
Some of the results of this paper were obtained by using the program package S.A.G.E., which is supported by a US Public Health Service Resource grant (RR03655) from the National Center for Research Resources. The authors thank all of the parents, teachers and children who participated.

\section{Declaration of Interest}

J.O. has been a member of the advisory board of Shire. J.B. has been a consultant to, member of advisory board of and/or speaker for Janssen Cilag BV, Eli Lilly, Bristol-Myers Squibb, UBC, Shire, Medice. J.A.S. has been a member of advisory board of Lilly, Shire, Janssen Cilag.

\section{References}

APA (1994). Diagnostic and Statistical Manual for Mental Disorders (DSM-IV), 4th edn. American Psychiatric Press: Washington, DC.

Ardila A, Pineda D, Rosselli M (2000). Correlation between intelligence test scores and executive function measures. Archives of Clinical Neuropsychology 15, 31-36.

Asarnow RF, Nuechterlein KH, Subotnik KL, Fogelson DL, Torquato RD, Payne DL, Asamen J, Mintz J, Guthrie D (2002). Neurocognitive impairments in nonpsychotic parents of children with schizophrenia and attentiondeficit/hyperactivity disorder. Archives of General Psychiatry 59, 1053-1060.

Barnett R, Maruff P, Vance A, Luk ESL, Costin J, Wood C, Pantelis C (2001). Abnormal executive functioning in attention deficit hyperactivity disorder: the effect of stimulant medication and age on spatial working memory. Psychological Medicine 31, 1107-1115.

Benson DF (1991). The role of frontal dysfunction in attention deficit hyperactivity disorder. Journal of Child Neurology 6 , 9-12.

Bidwell LC, Willcutt EG, DeFries JC, Pennington BF (2007). Testing for neuropsychological endophenotypes in siblings discordant for attention-deficit/hyperactivity disorder. Biological Psychiatry 62, 991-998.

Boonstra AM, Kooij JJS, Buitelaar JK, Oosterlaan J, Sergeant JA, Heister JGAMA, Franke B (2007). An exploratory study of the relationship between four candidate genes and neurocognitive performance in adult ADHD. American Journal of Medical Genetics Part B: Neuropsychiatric Genetics. Published online: 20 September 2007. doi :10.1002/ajmg.b.30595.

Boonstra AM, Oosterlaan J, Sergeant JA, Buitelaar JK (2005). Executive functioning in adult ADHD: a meta-analytic review. Psychological Medicine 35, 1097-1108.

Brookes K, Xu X, Chen W, Zhou K, Neale B, Lowe N, Aneey R, Franke B, Gill M, Ebstein R, Buitelaar J, Sham P, Campbell D, Knight J, Andreou P, Altink M, Arnold R, Boer F, Buschgens C, Butler L, Christiansen H, Feldman L, Fleischman K, Fliers E, Howe-Forbes R, Goldfarb A, Heise A, Gabriels I, Korn-Lubetzki I, Marco R, Medad S, Minderaa R, Mulas F, Muller U, Mulligan A,
Rabin K, Rommelse N, Sethna V, Sorohan J, Uebel H, Psychogiou L, Weeks A, Barrett R, Craig I,

Banaschewski T, Sonuga-Barke E, Eisenberg J, Kuntsi J, Manor I, McGuffin P, Miranda A, Oades R, Plomin R, Roeyers $\mathrm{H}$, Rothenberger A, Sergeant J, Steinhausen $\mathrm{H}$, Taylor E, Thompson M, Faraone S, Asherson P, Johansson L (2006). The analysis of 51 genes in DSM-IV combined type attention deficit hyperactivity disorder: association signals in DRD4, DAT1 and 16 other genes. Molecular Psychiatry 11, 934-953.

Bull R, Scerif G (2001). Executive functioning as a predictor of children's mathematics ability: inhibition, switching, and working memory. Developmental Neuropsychology 19, 273-293.

Castellanos FX, Tannock R (2002). Neuroscience of attention-deficit/hyperactivity disorder: the search for endophenotypes. Nature Reviews Neuroscience 3, 617-628.

Clark C, Prior M, Kinsella GJ (2000). Do executive function deficits differentiate between adolescents with ADHD and oppositional defiant/conduct disorder? A neuropsychological study using the Six Elements Test and Hayling Sentence Completion Test. Journal of Abnormal Child Psychology 28, 403-414.

Cohen J (1988). Statistical Power Analysis for the Behavioral Sciences, 2nd edn. Erlbaum: Hillsdale, NJ.

Conners K (1996). Rating Scales in ADHD. Duke University Medical Center: Durham, NC.

Conway AR, Kane MJ, Engle RW (2003). Working memory capacity and its relation to general intelligence. Trends in Cognitive Sciences 7, 547-552.

Crosbie J, Schachar R (2001). Deficient inhibition as a marker for familial ADHD. American Journal of Psychiatry 158, 1884-1890.

De Sonneville LMJ (1999). Amsterdam Neuropsychological Task: a computer-aided assessment program. In Cognitive Ergonomics, Clinical Assessment and Computer-Assisted Learning: Computers in Psychology, vol. 6 (ed. B. P. L. M. Den Brinker, P. J. Beek, A. N. Brand, S. J. Maarse and L. J. M. Mulder), pp. 204-217. Swets \& Zeitlinger: Lisse, The Netherlands.

Doyle AE (2006). Executive functions in attention-deficit/ hyperactivity disorder. Journal of Clinical Psychiatry 67 (Suppl. 8), 21-26.

Doyle AE, Biederman J, Seidman LJ, Reske-Nielsen JJ, Faraone SV (2005a). Neuropsychological functioning in relatives of girls with and without ADHD. Psychological Medicine 35, 1121-1132.

Doyle AE, Faraone SV, Seidman LJ, Willcutt EG, Nigg JT, Waldman ID, Pennington BF, Peart J, Biederman J (2005b). Are endophenotypes based on measures of executive functions useful for molecular genetic studies of ADHD? Journal of Child Psychology and Psychiatry 46, 774-803.

Duncan J (2005). Frontal lobe function and general intelligence: why it matters. Cortex 41, 215-217.

Duncan J, Burgess P, Emslie H (1995). Fluid intelligence after frontal lobe lesions. Neuropsychologia 33, 261-268. 
Duncan J, Emslie H, Williams P, Johnson R, Freer C (1996). Intelligence and the frontal lobe: the organization of goal-directed behavior. Cognitive Psychology 30, 257-303.

Durston S (2003). A review of the biological basis of ADHD What have we learned from imaging studies? Mental Retardation and Developmental Disabilities Research Reviews 9, 184-195.

Engle RW (2002). Working memory capacity as executive attention. Current Directions in Psychological Science 11, 19-23.

Faraone SV, Biederman J, Lehman BK, Spencer T, Norman D, Seidman LJ, Kraus I, Perrin J, Chen WJ, Tsuang MT (1993). Intellectual performance and school failure in children with attention deficit hyperactivity disorder and in their siblings. Journal of Abnormal Psychology 102, 616-623.

Faraone SV, Biederman J, Mennin D, Gershon J, Tsuang MT (1996). A prospective four-year follow-up study of children at risk for ADHD: psychiatric, neuropsychological, and psychosocial outcome. Journal of the American Academy of Child Adolescent Psychiatry 35, 1449-1459.

Frazier TW, Demaree HA, Youngstrom EA (2004). Meta-analysis of intellectual and neuropsychological test performance in attention-deficit/hyperactivity disorder. Neuropsychology 18, 543-555.

Fuster JM (1997). The Prefrontal Cortex: Anatomy, Physiology and Neuropsychology of the Frontal Lobe. Raven Press: New York.

Goodman R (1997). The strengths and difficulties questionnaire: a research note. Journal of Child Psychology and Psychiatry 38, 581-586.

Gottesman II, Gould TD (2003). The endophenotype concept in psychiatry: etymology and strategic intentions. American Journal of Psychiatry 160, 636-645.

Gray JR, Chabris CF, Braver TS (2003). Neural mechanisms of general fluid intelligence. Nature Neuroscience 6, 316-322.

Groth-Marnat G (1997). Handbook of Psychological Assessment, 3rd edn. Wiley: New York.

Haier RJ, Jung RE, Yeo RA, Head K, Alkire MT (2004). Structural brain variation and general intelligence. NeuroImage 23, 425-433.

Heilman KM, Voeller KKS, Nadeau SE (1991). A possible pathophysiological substrate of attention deficit hyperactivity disorder. Journal of Child Neurology 6, 76-81.

Khan SA, Faraone SV (2006). The genetics of ADHD: a literature review of 2005. Current Psychiatry Reports 8, 393-397.

Kuntsi J, Eley TC, Taylor A, Hughes C, Asherson P, Caspi A, Moffitt TE (2004). Co-occurrence of ADHD and low IQ has genetic origins. American Journal of Medical Genetics Neuropsychiatric Genetics 124B, 41-47.

Lezak MD (1995). Neuropsychological Assessment. Oxford University Press: New York.

Logan GD (1994). On the ability to inhibit thought and action: a users' guide to the stop signal paradigm. In Inhibitory Processes in Attention, Memory, and Language (ed. D. Dagenbach and T. H. Carr), pp. 189-239. Academic Press: San Diego.
Logan GD, Cowan WB (1984). On the ability to inhibit thought and action: a theory of an act of control. Psychological Review 91, 295-327.

Mahone EM, Hagelthorn KM, Cutting LE, Schuerholz LJ, Pelletier SF, Rawlins C, Singer HS, Denckla MB (2002) Effects of IQ on executive function measures in children with ADHD. Child Neuropsychology 8, 52-65.

Mariani MA, Barkley RA (1997). Neuropsychological and academic functioning in preschool boys with attention deficit hyperactivity disorder. Developmental Neuropsychology 13, 111-129.

Martinussen R, Hayden J, Hogg-Johnson S, Tannock R (2005). A meta-analysis of working memory impairments in children with attention-deficit/hyperactivity disorder. Journal of the American Academy of Child and Adolescent Psychiatry 44, 377-384.

Mattes JA (1980). The role of frontal lobe dysfunction in childhood hyperkinesis. Comprehensive Psychiatry 21, 358-369.

Mill J, Caspi A, Williams BS, Craig I, Taylor A, Polo-Tomas M, Berridge CW, Poulton R, Moffitt TE (2006). Prediction of heterogeneity in intelligence and adult prognosis by genetic polymorphisms in the dopamine system among children with attention-deficit/ hyperactivity disorder. Archives of General Psychiatry 63, 462-469.

Miyake A, Friedman NP, Emerson MJ, Witzki AH, Howerter A (2000). The unity and diversity of executive functions and their contributions to complex 'frontal lobe' tasks : a latent variable analysis. Cognitive Psychology 41, 49-100.

Miyake A, Friedman NP, Rettinger DA, Shah P, Hegarty M (2001). How are visuospatial working memory, executive functioning, and spatial abilities related? A latent-variable analysis. Journal of Experimental Psychology 130, 621-640.

Murphy KR, Barkley RA (1996). Parents of children with attention-deficit/hyperactivity disorder: psychological and attentional impairment. American Journal of Orthopsychiatry 66, 93-102.

Nigg JT (1999). The ADHD response-inhibition deficit as measured by the stop task: replication with DSM-IV combined type, extension, and qualification. Journal of Abnormal Child Psychology 27, 393-402.

Nigg JT, Blaskey LG, Huang-Pollock CL, Rappley MD (2002). Neuropsychological executive functions and DSM-IV ADHD subtypes. Journal of the American Academy of Child and Adolescent Psychiatry 41, 59-66.

Nigg JT, Blaskey LG, Stawicki JA, Sachek J (2004). Evaluating the endophenotype model of ADHD neuropsychological deficit: results for parents and siblings of children with ADHD combined and inattentive subtypes. Journal of Abnormal Psychology 113, 614-625.

Oosterlaan J, Logan GD, Sergeant JA (1998). Response inhibition in $\mathrm{AD} / \mathrm{HD}, \mathrm{CD}$, comorbid $\mathrm{AD} / \mathrm{HD}+\mathrm{CD}$, anxious, and control children: a meta-analysis of studies with the stop task. Journal of Child Psychology and Psychiatry $39,411-425$.

Oosterlaan J, Scheres A, Sergeant JA (2005). Which executive functioning deficits are associated with AD/HD, 
$\mathrm{ODD} / \mathrm{CD}$ and comorbid $\mathrm{AD} / \mathrm{HD}+\mathrm{ODD} / \mathrm{CD}$ ? Journal of Abnormal Child Psychology 33, 69-85.

Oosterlaan J, Sergeant JA (1996). Inhibition in ADHD, anxious and aggressive children: a biologically based model of child psychology. Journal of Abnormal Child Psychology 24, 19-36.

Pelham WE, Aronoff HR, Midlam JK, Shapiro CJ, Gnagy EM, Chronis AM, Onyango AN, Forehand G, Nguyen A, Waxmonsky J (1999). A comparison of ritalin and adderall: efficacy and time-course in children with attention-deficit/hyperactivity disorder. Pediatrics 103, e43.

Pennington BF, Ozonoff S (1996). Executive functions and developmental psychopathology. Journal of Child Psychology and Psychiatry 37, 51-87.

Plomin R, Spinath FM (2005). Intelligence: genetics, genes, and genomics. Journal of Personality and Social Psychology 86, 112-129.

Polderman TJ, Gosso MF, Posthuma D, Van Beijsterveldt TC, Heutink P, Verhulst FC, Boomsma DI (2006). A longitudinal twin study on IQ, executive functioning, and attention problems during childhood and early adolescence. Acta Neurologica Belgica 106, 191-207.

Rommelse NNJ, Oosterlaan J, Buitelaar J, Faraone SV, Sergeant JA (2007). Time reproduction in children with ADHD and their non-affected siblings. Journal of the American Academy of Child and Adolescent Psychiatry 46, 582-590.

Schachar RJ, Crosbie J, Barr CL, Ornstein TJ, Kennedy J, Malone M, Roberts W, Ickowicz A, Tannock R, Chen S, Pathare T (2005). Inhibition of motor responses in siblings concordant and discordant for attention deficit hyperactivity disorder. American Journal of Psychiatry 162, 1076-1082.

Scheres A, Oosterlaan J, Sergeant JA (2006). Speed of inhibition predicts teacher-rated medication response in boys with attention deficit hyperactivity disorder. Journal of Disability, Development and Education 1, 93-109.

Schretlen D, Pearlson GD, Anthony JC, Aylward EH, Augustine AM, Davis A, Barta P (2000). Elucidating the contributions of processing speed, executive ability, and frontal lobe volume to normal age-related differences in fluid intelligence. Journal of the International Neuropsychological Society 6, 52-61.

Seidman L, Biederman J, Monuteaux M, Weber W, Faraone SV (2000). Neuropsychological functioning in nonreferred siblings of children with attention deficit hyperactivity disorder. Journal of Abnormal Psychology 109, 252-265.

Seidman L, Doyle A, Fried R, Valera E, Crum K, Matthews L (2004). Neuropsychological functioning in adults with attention-deficit/hyperactivity disorder. Psychiatric Clinics of North America 27, 261-282.
Seidman LJ, Biederman J, Faraone SV, Milberger S, Norman D, Seiverd K, Benedict K, Guite J, Mick E, Kiley K (1995). Effects of family history and co-morbidity on the neuropsychological performance of children with ADHD: preliminary findings. Journal of the American Academy of Child and Adolescent Psychiatry 34, 1015-1024.

Sergeant JA, Geurts H, Oosterlaan J (2002). How specific is a deficit of executive functioning for attention-deficit/ hyperactivity disorder? Behavioural Brain Research 130, 3-28.

Slaats-Willemse D, Swaab-Barneveld H, De Sonneville L, Buitelaar J (2005). Familial clustering of executive functioning in affected sibling pair families with ADHD. Journal of the American Academy of Child and Adolescent Psychiatry 44, 385-391.

Slaats-Willemse D, Swaab-Barneveld H, De Sonneville L, Van der Meulen E, Buitelaar J (2003). Deficient response inhibition as a cognitive endophenotype of ADHD. Journal of the American Academy of Child and Adolescent Psychiatry 42, 1242-1248.

Smith EE, Jonides J (1999). Storage and executive processes in the frontal lobe. Science 283, 1657-1661.

Stuss DT, Benson DF (1986). The Frontal Lobes. Raven Press: New York.

Tabachnick BG, Fidell LS (2001). Using Multivariate Statistics, 4th edn. Allyn and Bacon: Needham Heights, MA.

Taylor EA (1986). Childhood hyperactivity. British Journal of Psychiatry 149, 562-573.

Toga AW, Thompson PM (2005). Genetics of brain structure and intelligence. Annual Review of Neuroscience 28, 1-23.

Waldman ID (2005). Statistical approaches to complex phenotypes: evaluating neuropsychological endophenotypes for attention-deficit/hyperactivity disorder. Biological Psychiatry 57, 1347-1356.

Waldman ID, Nigg JT, Gizer IR, Park L, Rappley MD, Friderici K (2006). The adrenergic receptor $\alpha$-2A gene (ADRA2A) and neuropsychological executive functions as putative endophenotypes for childhood ADHD. Cognitive, Affective, and Behavioral Neuroscience 6, 18-30.

Wechsler D (1944). The Measurement of Adult Intelligence. Williams and Wilkins: Baltimore.

Wechsler D (2000). WAIS-III Nederlandstalige Bewerking. Technische Handleiding. The Psychological Corporation: London.

Wechsler D (2002). WISC-III Handleiding. The Psychological Corporation: London.

Welsh MC, Pennington BF, Groisser DB (1991). A normative-developmental study of executive function: a window on prefrontal function in children. Developmental Neuropsychology 7, 131-149.

Willcutt EG, Doyle AE, Nigg JT, Faraone SV, Pennington BF (2005). Validity of the executive function theory of attention-deficit/hyperactivity disorder: a meta-analytic review. Biological Psychiatry 57, 1336-1346. 